\title{
A concepção de filosofia da educação no pensamento de John Dewey
}

\author{
The conception of philosophy of education in John Dewey's thought
}

Rodrigo Augusto de Souza*

\section{Resumo}

Este artigo apresenta aspectos da concepção de filosofia da educação elaborada por John Dewey (1859-1952) em sua obra Democracia e educação, publicada pela primeira vez em 1916. A hipótese que orienta o trabalho é a de que a noção de filosofia da educação perpassa todo o livro de Dewey, considerado sua obra-prima (masterpiece). Dewey defendeu a tese de que a filosofia deveria ser considerada a teoria geral da educação. Procura-se desenvolver essa conceituação realizada pelo filósofo norte-americano. A filosofia recebeu uma importante função social, cultural e pedagógica no pensamento deweyano. Isso tinha por objetivo realizar a crítica dos sistemas filosóficos clássicos, como o estoicismo, a escolástica, o racionalismo, o empirismo, o idealismo e o liberalismo. Além disso, a proposta filosófica de Dewey objetivava livrar a reflexão filosófica da esterilidade e da inércia. Em outras palavras, incentivar a colaboração da filosofia com a sociedade e a cultura. Nesse propósito, a educação teria um lugar de destaque. Não obstante o papel fundamental desempenhado pela filosofia na educação, é possível também identificar algumas críticas a essa atribuição. A crítica consiste no argumento de que Dewey defendeu uma concepção instrumental da filosofia, distante da crítica.

Palavras-chave: Democracia e Educação. Educação. Filosofia. John Dewey.

\section{Abstract}

This article presents aspects of the conception of philosophy of education elaborated by John Dewey (18591952), in his book Democracy and education, published in 1916. The hypothesis that guides the study is that the notion of philosophy of education pervades the whole Dewey's book, considered his masterpiece. Dewey defended the thesis that philosophy should be considered the general theory of education. It seeks to develop this conceptualization carried out by the American philosopher. The Philosophy received an important social function, cultural and pedagogical in Deweyan thought. This was intended to carry out the critique of classical philosophical systems, such as Stoicism, Scholasticism, Rationalism, Empiricism, Idealism and Liberalism. In addition, Dewey's philosophical proposal aimed at ridding philosophical reflection of sterility and inertia. In other words, encourage the collaboration of philosophy, with society and culture. In this regard education would have a prominent place. Nevertheless, the fundamental role played by philosophy in education, it is also possible to identify some criticisms of this attribution. Such criticism consists in the argument that Dewey defended an instrumental conception of philosophy, far from critical.

Keywords: Democracy and Education. Education. Philosophy. John Dewey.

Recebido em 29/07/2017 - Aprovado em 13/12/2017

http://dx.doi.org/10.5335/rep.v25i1.8034

Doutor em Educação pela Universidade Federal do Paraná. Realizou pós-doutorado com bolsa da Coordenação de Aperfeiçoamento de Pessoal de Nível Superior na Universidade Estadual de Ponta Grossa. Professor adjunto da Faculdade de Educação da Universidade Federal de Mato Grosso do Sul. E-mail: rodrigoaugustobr@gmail.com 


\section{Introdução}

A obra Democracia e educação (1979), publicada pela primeira vez em 1916, de John Dewey (1859-1952), tem uma importância capital para o entendimento do pensamento do filósofo norte-americano, de tal modo que podemos argumentar que ela é a obra-prima (masterpiece) de Dewey, que representa e resume as suas principais ideias. Entre os capítulos mais importantes da publicação está aquele que trata da filosofia da educação e que constitui o objeto de estudo do presente artigo. O livro em questão é uma obra-testemunha, na acepção indicada por Pierre Bourdieu (2015, p. 284), isto é, representa o capital cultural (e também escolar) objetivado pelo pensador.

Essa noção forjada por Bourdieu mostra-se útil para analisar a trajetória (vida), a obra e o pensamento de Dewey. A obra-testemunha permite ainda identificar a formação social, os códigos intelectuais, culturais e sociais utilizados pelo autor por meio de sua aprendizagem, institucionalizada ou não. Além disso, ela também viabiliza o reconhecimento de seu autor, de tal maneira que ele seja reconhecido pela obra, por suas propriedades estilísticas (portanto, estéticas). Porém, esse tipo de obra funciona como um código que requer interpretação, para que, por meio dela, seja dada a conhecer uma determinada época, uma dada escola e um dado autor. Esse é o intento do presente estudo, tendo como foco específico a concepção de filosofia da educação forjada tal como está na obra, que recentemente comemorou o centenário de sua publicação.

O estudo insere-se entre os demais trabalhos que, no campo educacional brasileiro, procuram investigar o pensamento deweyano, dentre os quais se destacam Pitombo (1974), Schmitz (1980), Amaral (1990), Cunha (1998, 2001), Warde (2013), Galiani (2009) e Fávero e Tonietto (2011). É preciso levar em conta o número considerável de pesquisas (teses e dissertações) realizadas sobre o pensamento de Dewey, bem como os artigos publicados em periódicos científicos e os trabalhos divulgados em anais de eventos acadêmicos. Isso, por si, já confere ao estudo sobre o processo de interpretação e apropriação do pensamento deweyano no Brasil uma significativa complexidade, uma vez que o trabalho supõe mapear e analisar a produção acadêmica e/ou científica realizada em nosso país.

Dewey afirmou, em Democracia e educação, estar "tratando de filosofia da educação" (1979, p. 354) ao longo de toda a obra. Mas o fez de modo difuso. Nesse empenho, segundo o autor, no capítulo 24, tornaram-se necessários "uma definição de filosofia" e "um exame da natureza de uma filosofia da educação" (DEWEY, 1979, p. 354). Assim, o filósofo pretendeu realizar uma "revisão crítica" do livro (na sua ordem lógica), o que cumpriu de fato. A proposta do capítulo foi discutir, 
"em moldes mais especificamente filosóficos", as "teorias do conhecimento e da moral subentendidas nos diversos ideais educacionais, quando postos em prática" (DEWEY, 1979, p. 354). O objetivo do estudo ficou mais nítido, isto é, deter-se nas "teorias do conhecimento e da moral", implícitas nos "ideais" (ou teorias) educacionais, submetidos ao critério da prática.

\section{Uma revisão crítica da obra}

Na análise que realizou de sua obra, Dewey (1979) a dividiu em três partes: 1) do capítulo I ao V; 2) do capítulo VI ao VII e do XIII ao XIV; e 3) do capítulo XVIII ao XXIII. Essa seria a estrutura principal do livro, segundo o pensador. Na primeira parte, mostrou-se a educação como necessidade e função sociais (DEWEY, 1979, p. 354). Foi apresentada a definição de que a "educação é o processo de renovação das significações da experiência", que seria "instituída para operar a continuidade social” (DEWEY, 1979, p. 354). A educação é vista como forma de socialização da criança e, portanto, com uma função social bastante definida. Seria, igualmente, uma forma da "direção e do desenvolvimento dos indivíduos imaturos e do grupo em que eles vivem" (DEWEY, 1979, p. 354). Essa caracterização da pedagogia de Dewey permite-nos afastá-la das compreensões equivocadas que a consideram como um "espontaneísmo pedagógico" ou um "autodidatismo", no qual a criança aprende apenas o que quer, de acordo com seus interesses particulares. O favorecimento de interesses compartilhados, por meio da educação progressiva, no seio de sociedades plenamente democráticas, foi a marca da pedagogia deweyana. Por isso, o filósofo norte-americano tinha o intuito de promover a "educação apropriada ao desenvolvimento de uma sociedade democrática" (DEWEY, 1979, p. 355).

Na segunda parte do livro, Dewey expôs a defesa do "critério democrático", visto como "contínua reconstrução ou reorganização da experiência, de natureza a aumentar a reconhecida significação ou conteúdo social da mesma" (DEWEY, 1979 , p. 355). Houve a preocupação de "delinear os caracteres respectivos da matéria de estudo e do método" (DEWEY, 1979, p. 355). Ainda, "o método de estudar e aprender sobre esta base é precisamente o movimento conscientemente dirigido para a reorganização da matéria da experiência" (DEWEY, 1979, p. 355). Foram apresentados por Dewey os "princípios essenciais do método e da matéria de ensino (caps. XIII-XIV)” (DEWEY, 1979, p. 355).

Por sua vez, na terceira e última divisão da obra operada pelo autor (caps. XVIII-XXIII), foi desenvolvida uma análise crítica sobre "o critério democrático e sua aplicação na vida social presente" (DEWEY, 1979, p. 355). Tratou-se das "limitações de que a experiência consiste em uma variedade de domínios ou interesses 
segregados uns dos outros, tendo cada qual seu valor, seu material e seu método independentes e próprios, em colisão uns com os outros" (DEWEY, 1979, p. 355). Isso seria responsável por um "equilíbrio de poderes na educação" (DEWEY, 1979, p. 355). Para Dewey, essas tensões e embates "se originavam nas divisões da sociedade em classes e grupos mais ou menos rigidamente demarcados" (DEWEY, 1979, p. 355). A divisão da sociedade em classes era um obstáculo à unidade da experiência. Os "dualismos e antíteses" que obstaculizavam a unidade da experiência eram "o do trabalho e o do gozo de lazeres, da atividade prática e intelectual, do homem e da natureza, da individualidade e da associação, da cultura e da vocação" (DEWEY, 1979, p. 356). A intenção contínua do pensamento de Dewey foi superar esses dualismos que marcaram os sistemas filosóficos clássicos, nos quais se encerram os principais problemas da filosofia, em vista da recuperação da unidade da experiência.

Com o propósito de evitar as separações que marcavam os sistemas filosóficos, por exemplo: "do espírito e da matéria, do corpo e do espírito, do espírito e do mundo, do indivíduo e suas relações com os outros indivíduos" (DEWEY, 1979, p. 356), Dewey elaborou sua filosofia. Entre todas as separações, a maior seria "a separação entre o espírito ou mente e a atividade que exigisse condições físicas, órgãos corpóreos, recursos materiais e objetos naturais" (DEWEY, 1979, p. 356). Seu propósito foi elaborar "uma filosofia que reconhecesse a origem, o papel e a função do espírito em uma atividade que influencia e dirige o ambiente" (DEWEY, 1979, p. 356, grifo do autor).

A filosofia de Dewey (1979) foi definida por ele mesmo como humanismo naturalista e/ou naturalismo humanista (CUNHA, 1998). Desse modo, o filósofo pretendia reunir dois temas centrais da sua teoria filosófica: humanismo e naturalismo, advindos da influência recebida por ele de pensadores importantes, como Immanuel Kant (1724-1804)1 e Charles Darwin (1809-1882) ${ }^{2}$ (CRUZ; CUNHA, 2016).

Assim, reuniu os temas da "continuidade biológica dos impulsos e instintos humanos com as energias naturais" (DEWEY, 1979, p. 356). De acordo com o pensador, "o desenvolvimento do espírito" dependeria "da participação em atividades conjuntas com um objetivo comum", com "a influência do ambiente físico por meio da utilização do ambiente social, a necessidade da utilização das variações individuais de desejos e pensamentos para uma sociedade que se desenvolva progressivamente" (DEWEY, 1979, p. 356). Deveria haver a "unidade essencial entre método e matéria, a continuidade intrínseca dos fins e dos meios, o reconhecimento do ser, o espírito ou a mente, o ato de pensar que percebe e submete à prova as significações do comportamento" (DEWEY, 1979, p. 356). Esta era uma preocupação constante na filosofia deweyana: superar os dualismos que haviam caracterizado 
a história da filosofia. Por meio desses argumentos, o filósofo já apresentava os pressupostos da sua filosofia: "essas concepções se coadunam com a filosofia que vê a inteligência como a reorganização com um fim, mediante a ação, do material da experiência" (DEWEY, 1979, p. 356). Mais ainda, tais atividades "não se harmonizam com qualquer das filosofias dualistas mencionadas" (DEWEY, 1979, p. 356). Predominantemente, a filosofia deweyana pretendia ser uma forma de superação dos dualismos e antagonismos dos sistemas filosóficos clássicos.

\section{0 conceito de filosofia}

No capítulo 24 de Democracia e educação, Dewey argumenta que era chegado o momento de "extrair e tornar explícito o conceito de filosofia" (1979, p. 356). Ao filósofo norte-americano, convém a definição de Deleuze e Guattari: "o filósofo é o amigo do conceito, ele é o conceito em potência [...] criar conceitos sempre novos é o objeto da filosofia" (2013, p. 11). Pois, segundo as palavras de Dewey, "descrevemos a filosofia, embora sem a definirmos, mencionando os problemas de que trata e salientamos que esses problemas se originam dos conflitos e dificuldades da vida social" (1979, p. 357). Entre esses problemas, figuravam "as relações entre o espírito e a matéria, o corpo e alma, a humanidade e a natureza física, o individual e social, a teoria (ou conhecimentos) e a prática (ou ação)" (DEWEY, 1979, p. 357). Eram os antagonismos inerentes ao pensamento filosófico ocidental. Dewey procurou superá-los no seu projeto de reconstrução da filosofia, tal como apresentou em sua obra A filosofia em reconstrução (1958), publicada pela primeira vez em 1920.

Segundo Dewey (1979), havia uma articulação entre os sistemas filosóficos e as práticas sociais contemporâneas. Tais sistemas "tornam manifestamente consciente aquilo que os homens chegaram a pensar em virtude da qualidade de sua experiência corrente sobre a natureza, sobre eles próprios e sobre a realidade que em sua concepção encerra ou governa essas duas coisas" (DEWEY, 1979, p. 357). Dewey entendeu que "a filosofia foi geralmente definida de modo a implicar uma certa totalidade, generalidade e última causalidade (ultimateness) da matéria e do método" (DEWEY, 1979, p. 357). O conceito de filosofia foi definido mais claramente da seguinte forma: 
A filosofia é uma tentativa de compreender, isto é, reunir as várias particularidades do mundo e da vida em um todo único que seja uma unidade, ou, como nos sistemas dualistas, reduzir a pluralidade de particularidades a um número pequeno de princípios finais. No referente à atitude do filósofo e daqueles que aceitam suas conclusões, há o esforço para conseguir-se uma visão da experiência o mais unificada, coerente e completa possível. Este aspecto é expresso pela palavra "filosofia" - amor à sabedoria. Sempre a filosofia foi encarada a sério, presumiu-se que ela significava conseguir uma sabedoria que influenciasse o procedimento e a direção da vida. Testemunha isto a circunstância de que quase todas as antigas escolas filosóficas eram também modos de viver organizados, sendo requerido, daqueles que aceitavam seus dogmas, adotar certos modos distintivos de proceder; também o comprovam a íntima associação da filosofia com a teologia da Igreja Romana na Idade Média, sua frequente associação com interesses religiosos, e, nas crises nacionais, sua associação com as lutas políticas (DEWEY, 1979, p. 357).

Dewey defendeu o "caráter instrumental da filosofia e propugnou a aplicação da crítica filosófica à realidade circundante" (AMARAL, 1990, p. 22). Por isso, sua filosofia foi designada de instrumentalismo. Tal afirmação está bem evidente no excerto apresentado. Há uma articulação intrínseca entre a filosofia, o mundo e a vida. Os indícios da formação hegeliana de Dewey ficam visíveis, já que "profundamente influenciado pela tradição neo-hegeliana, ele começou as premissas da sua interpretação do pragmatismo instrumentalista com claras referências ao evolucionismo, fundando naquele período com G. H. Mead aquela que será chamada a Escola de Chicago" (CAPPA, 2014, p. VI, tradução nossa). A concepção de filosofia subjacente a essa ideia encontra referência na noção elaborada por Hegel (17701831) de Weltweisheit (sabedoria mundana). A filosofia como sabedoria mundana está articulada com as principais questões inerentes à vida. Mas a ideia da filosofia na forma de uma unidade ou uma síntese universal é também uma herança hegeliana. As diferentes doutrinas filosóficas sempre foram acompanhadas de modos de viver e tiveram repercussões morais, religiosas e políticas ao longo da história.

Bernstein (2015, p. 110) mostrou que a incidência de Hegel no pensamento de Dewey foi "enorme". Entretanto, isso só ocorreu depois que o filósofo se transferiu da Universidade de Vermont, no seu estado de origem, para a Universidade Johns Hopkins, em Maryland. Durante seus estudos "especializados em filosofia, recebidos de G. S. Morris, um entusiasta de Hegel e do idealismo, [o hegelianismo] começou a exercer uma importante influência sobre ele” (BERNSTEIN, 2015, p. 110, tradução nossa). Essa foi a característica daquilo que Richard Bernstein chamou de "primeiro Dewey" (2015, p. 110) ou "jovem Dewey" (2015, p. 111). Perguntou o estudioso do pragmatismo: "O que encontrou de interessante em Hegel o jovem Dewey?" (BERNSTEIN, 2015, p. 111); e respondeu: "Isso que Dewey encontrou de assim sedutor foi o sentido da vida, o dinamismo e, de modo especial, a visão de uma realidade organicamente interconectada" (BERNSTEIN, 2015, p. 111). Mas, 
para o autor, "a despeito dessa fascinação inicial, Dewey se distanciou de Hegel" (BERNSTEIN, 2015, p. 112). E, logo em seguida, "Darwin tomou o lugar de Hegel qual fonte de inspiração para o caráter orgânico, dinâmico e mutável da vida” (BERNSTEIN, 2015, p. 112). Não obstante sua ulterior adesão a Darwin, o filósofo norte-americano não se viu livre das contribuições recebidas de Hegel no período do seu doutorado em Baltimore.

No conceito de filosofia forjado por Dewey, há "esta direta e íntima conexão da filosofia com uma visão da vida", e isso, por sua vez, "a diferencia da ciência" (DEWEY, 1979, p. 357). "Evitou-se, desse modo, a tentativa da fenomenologia de Edmund Husserl (1859-1938), e mesmo do positivismo, de transformar a filosofia numa ciência rigorosa ao modo das ciências da natureza" (BAIRATI, 2014, p. 5, tradução nossa). Assinalou Dewey: "Quando a ciência, porém, não significa simplesmente um catálogo dos fatos particulares descobertos sobre mundo e sim uma atitude geral para com este - encarando-se essa atitude como distinta das coisas especiais a fazer - ela passa a ser filosofia" (1979, p. 357-358). O filósofo procurou a especificidade própria da filosofia frente às demais ciências, como a matemática, a física, a química, a biologia, a antropologia, a história, etc. Argumentou que "às ciências é que compete dizer quais as generalizações admissíveis sobre o mundo e quais, especificamente, são elas" (DEWEY, 1979, p. 358). Assim, a filosofia teria uma função de orientar a atitude do indivíduo diante do mundo: "Mas quando perguntamos que espécie de atitude permanente ativa para com o mundo as revelações científicas exigem de nós, estamos a formular uma questão filosófica" (DEWEY, 1979, p. 358).

Dewey evitou o culto cego dos fatos científicos à maneira positivista. Reiterou que mesmo "o prisma [da] 'totalidade' não significa a tarefa impossível de uma acumulação quantitativa" (DEWEY, 1979, p. 358). Repetiu também que "totalidade significa continuidade - o prosseguimento de um primeiro hábito de agir com a readaptação necessária para conservá-lo vivo e em evolução" (DEWEY, 1979, p. 358). A filosofia não seria um privilégio de uma casta favorecida (os filósofos), mas "toda pessoa de espírito franqueado e sensível a novas percepções e que profunda e responsavelmente lhes percebe as relações entre si terá, na proporção em que 0 fizer, uma atitude filosófica" (DEWEY, 1979, p. 358). Mais adiante, Dewey criticou "um dos sentidos populares da filosofia que é a calma e a longanimidade em face dos obstáculos e das perdas sofridas; supõe-se, mesmo, ser a faculdade de se sofrer sem se queixar" (DEWEY, 1979, p. 358-359). Criticou essa filosofia popular considerando-lhe antes "uma homenagem à influência da filosofia estoica, do que um atributo da filosofia em geral” (DEWEY, 1979, p. 359). 
É sabido que as filosofias estoica e cristã (escolástica) sempre foram alvos das críticas do filósofo estadunidense (DEWEY, 1980). Ao passo que seu pensamento valorizava - no que concerne à filosofia grega - a experiência do epicurismo, por exemplo. Porém, mesmo mostrando suas dificuldades, reconheceu-lhe o valor: "se justifica na proporção em que sugerir que toda a característica da filosofia é a faculdade de aprender, de extrair significações até das desagradáveis vicissitudes da vida e transformar aquilo que foi aprendido em aptidão para continuar a aprender" (DEWEY, 1979, p. 359). Justificou o pensador que a finalidade não consistia em que a experiência estivesse "finda e esgotada e sim à disposição de atingir níveis mais profundos de significação" (DEWEY, 1979, p. 359). A noção de filosofia apareceu aliada à experiência, pois "a atitude filosófica é geral no sentido de ser adversa a tomar as coisas isoladamente; intenta colocar um ato no todo a que pertence - e que lhe dá significação" (DEWEY, 1979, p. 359).

A experiência e o todo são elementos importantes nessa afirmação. Quanto ao último, é mais um indício da herança hegeliana no pensamento de Dewey. Compreendemos que, para Hegel, foi certa a máxima de que o verdadeiro é o todo, isto é, todo o conhecimento aspira a universalidade. Disso resulta a preocupação deweyana de superar as dicotomias que marcaram os sistemas filosóficos e recuperar a unidade do conhecimento. Outro aspecto é a significação, que consiste em elaborar um conhecimento que faça sentido ao indivíduo e à comunidade humana. A ideia de significação está muito próxima da psicologia, uma vez que Dewey inovou ao defender a adequação do currículo escolar ao desenvolvimento psicológico da criança, conforme descreveu em A criança e o programa escolar (1978), publicada pela primeira vez em 1902.

É de vantagem identificar a filosofia com o ato de pensar enquanto distinta do conhecimento. O conhecimento, isto é, o conhecimento fundamentado é ciência; ele representa as coisas que foram estabelecidas, ordenadas, dispostas racionalmente. Quanto ao ato de pensar, aplica-se a coisas em perspectiva. É ocasionado por uma incerteza e visa dissipar uma perturbação. Filosofia é pensar o que aquilo que é conhecido requer da nossa parte qual a atitude de cor+respondência que ele exige. É uma ideia do que é possível, não um registro de fatos consumados. Por essa razão é hipotética, assim como todo o ato de pensar. Ela assinala alguma coisa a ser feita - alguma coisa a ser tentada. Seu valor não está em proporcionar soluções (o que só pode ser conseguido com a ação) e sim em analisar as dificuldades e sugerir métodos para nos avirmos delas. Pode-se quase definir a filosofia como o pensamento que se tornou consciente de si mesmo - que generalizou seu lugar, função e valor na experiência (DEWEY, 1979, p. 359, grifos do autor).

Algumas ideias dessa definição explicitada merecem destaque, tais como: a articulação da filosofia com o ato de pensar, a correspondência, a hipótese, a análise das dificuldades e a sugestão de métodos (FREGA, 2008). A filosofia seria uma forma de pensamento (consciente de si mesmo, à moda hegeliana), que generaliza, ou 
seja, busca a universalidade, ela tem seu lugar, sua função e seu valor na experiência. O conceito de experiência tem outros contornos no instrumentalismo de Dewey, divergindo, assim, do empirismo clássico e do positivismo. A experiência é algo muito mais amplo do que a sua dimensão gnosiológica, é a própria marcha da vida.

Chomsky (2017) referiu-se à polêmica envolvendo o instrumentalismo de Dewey durante a Primeira Guerra Mundial, pois o filósofo:

[...] ficou impressionado pela formidável "lição psicológica e educacional" da guerra, que provava que os seres humanos - mais precisamente, "homens inteligentes da comunidade" - são capazes de "apoderar-se dos assuntos humanos e lidar com eles [...] deliberada e inteligentemente” de modo a alcançar os fins almejados (CHOMSKY, 2017, p. 15).

Para Bairati (2014), no contexto da guerra, o instrumentalismo conduziu "uma controlada, porém severa polêmica contra o pacifismo" (2014, p. 7, tradução nossa).

Dewey insistiu na necessidade de que a filosofia fosse concebida numa "atitude total por existir a necessidade de integrar na ação os vários interesses em conflito da vida" (1979, p. 360). Considerou que as "filosofias caseiras são legítimas e muitas vezes adequadas" (DEWEY, 1979, p. 360). Sua compreensão da filosofia não era elitista e tão pouco academicista, porém, entendeu que essas filosofias populares "não resultam em sistemas filosóficos" (DEWEY, 1979, p. 360). Pelo contrário, surgem "quando as exigências mutuamente discrepantes de diferentes ideais de conduta atingem a sociedade como um todo e torna-se geral a necessidade de reajustamento" (DEWEY, 1979, p. 360). Ou seja, as filosofias caseiras mostram o impasse (ou a crise) entre os sistemas filosóficos clássicos e a conduta da sociedade. O intento de Dewey é justamente aproximar a filosofia da vida social, de modo que seja eliminado o antagonismo entre indivíduo e sociedade ou entre a ideia e a realidade. Para o pensador, a filosofia não deve ser estudada "por si mesma, como apenas exercício de agilidade intelectual ou de severa disciplina - como coisa dita pelos filósofos que se refira só a eles" (DEWEY, 1979, p. 360).

\section{A teoria geral da educação}

Para Dewey (1979), as conclusões filosóficas deveriam ser confrontadas "com a espécie de disposição mental a que correspondem, ou com as diferenças que operam na prática educativa quando influem sobre ela" (DEWEY, 1979, p. 361-362). A inovação consistiu em defender a necessidade de confrontar a filosofia com a prática educativa, pois "a teoria que não influencia a atividade educativa é uma teoria artificial” (DEWEY, 1979, p. 362). E, mais ainda, há a defesa de que as ideias filosóficas devem influenciar a educação. A filosofia somente cumpriria sua função social sendo educativa. Nas ideias deweyanas, existe uma conexão entre o 
"ponto de vista educacional" e os "problemas filosóficos". Por isso, "o ponto de vista educacional habilita-nos a encarar os problemas filosóficos no terreno em que surgem e lutam, na sua própria casa, por assim dizer, local em que a sua aceitação ou rejeição resulta em uma diferença na prática” (DEWEY, 1979, p. 362).

O filósofo propugnou, conforme justificou Saviani, que "toda educação deve ter uma orientação filosófica", valorizou a "dimensão filosófica da educação" e admitiu "que a filosofia desempenha um papel imprescindível na formação do educador" (2013a, p. 11). Além disso, foi além ao entender que a função da filosofia no currículo mínimo dos cursos de pedagogia não deve ser "mero fruto da tradição", mas efetivamente levar "o educador a filosofar" (SAVIANI, 2013a, p. 11). Mas Saviani discordou de Dewey sobre a ideia de que a filosofia é uma teoria geral da educação, o que, em sua opinião, seria reduzir o seu papel. Saviani salientou que a função da filosofia da educação "será acompanhar reflexiva e criticamente a atividade educacional de modo que explicite os seus fundamentos, esclarecer a tarefa e a contribuição das diversas disciplinas pedagógicas e avaliar o significado das soluções escolhidas" (2013a, p. 29). Como defendeu Pitombo (1974), por sua formação kantiana, Dewey adotou o criticismo como um postulado metodológico da sua filosofia. O que significa afirmar que, ao defender a filosofia como teoria geral da educação, o pensador não está abdicando necessariamente de sua função crítica.

Não é apenas quanto à concepção de filosofia da educação que a crítica de Saviani pode ser aplicada a Dewey, mas, principalmente, pela tese defendida em Escola e democracia, de que a Escola Nova não é democrática (SAVIANI, 1999). Tal crítica atinge o cerne da filosofia deweyana, contudo, deve ser lida em um contexto de apropriação do marxismo brasileiro bastante discutível. A compreensão de Saviani quanto à filosofia da educação consiste em: "reflexão (radical, rigorosa e de conjunto) sobre os problemas que a realidade educacional apresenta" (SAVIANI, 2013b, p. 69). Completa que, "como tal, não lhe cabe a tarefa específica de definir a priori a educação nem sistematizá-la a posteriori numa teoria geral, como fazem crer as abordagens convencionais, mas acompanhar reflexiva e criticamente a ação pedagógica" (SAVIANI, 2013b, p. 69). Assim, mais uma vez, encontramos uma posição oposta à de Dewey, para a quem a filosofia é a teoria geral da educação.

Numa perspectiva diversa, Dewey sustentou que "se quisermos conceber a educação como processo de formar atitudes fundamentais, de natureza intelectual e sentimental, perante a natureza e os outros homens, pode-se até definir a filosofia como a teoria geral da educação" (1979, p. 362), mas reiterou que a filosofia não deve se limitar "a permanecer simbólica - ou verbal - ou um deleite sentimental para poucos, ou então como meros dogmas arbitrários, seu exame da experiência passada e seu programa de valores devem influir na conduta" $(1979$, p. 362). A filosofia tem uma função social, que é educativa, isto é, modifica "a atitude mental e moral" (DEWEY, 1979, p. 362). Ainda, deve ajudar a romper com a atividade 
escolar "empírica e rotineira", animando-a com "uma visão ampla e generosa de seu papel na vida contemporânea" (DEWEY, 1979, p. 362). A dimensão educativa da filosofia diz respeito tanto à mudança de atitudes mentais e morais quanto à superação da monotonia e de rotinas escolares.

A filosofia tem, assim, dupla tarefa; a de criticar os objetivos existentes com relação ao estado atual da ciência, indicando os valores que se tornaram obsoletos em vista dos novos recursos disponíveis e quais os que são meramente sentimentais por não constituírem meios para a realização daqueles objetivos; e também a de interpretar os resultados da ciência especializada, em seu alcance sobre os futuros empreendimentos sociais. Seria impossível que ela tivesse bom êxito nessas tarefas, sem equivalentes educacionais sobre o que se devesse fazer ou não fazer. Pois a teoria filosófica não dispõe de uma lâmpada de Aladim para fazer surgir de repente os valores que ela "constrói” intelectualmente [...]. A educação é o laboratório onde as distinções filosóficas são concretizadas e postas à prova (DEWEY, 1979, p. 363).

No entendimento de Dewey, a filosofia europeia se originou "(entre os atenienses) sob compreensão direta das questões educacionais” (1979, p. 363). E o pensador vai além ao argumentar que "os sofistas formam o primeiro corpo de professores profissionais na Europa” (DEWEY, 1979, p. 363). O papel dos sofistas foi destacado porque:

[...] instruíam os jovens sobre a virtude, sobre as artes políticas e sobre a direção do estado e das coisas domésticas, a filosofia começou a tratar das relações entre o individual com o universal, com alguma classe compreensiva ou com algum grupo - das relações do homem com a natureza, da tradição com a reflexão, do conhecimento com a ação (DEWEY, 1979, p. 363).

Dewey identificou o surgimento da profissão docente como estreitamente ligado à filosofia grega, sobretudo ao trabalho dos sofistas.

Mas o fato de que a corrente do pensamento filosófico europeu surgiu como a teoria do processo educacional testifica com eloquência a íntima associação da filosofia e da educação. A "filosofia da educação" não é a aplicação exterior de ideias já feitas a um sistema de prática escolar que tivesse origem e meta radicalmente diversas: é apenas uma formulação explícita dos problemas da formação de uma mentalidade reta e de bons hábitos morais, tendo-se em vista as dificuldades da vida social contemporânea. A mais profunda definição de filosofia que se possa dar é a de ser a teoria da educação em seus aspectos mais gerais. A reconstrução da filosofia, a da educação e dos ideais e métodos sociais, caminham, assim, de mãos dadas. Se é verdade que existe, nos tempos atuais, uma necessidade especial de reconstrução educativa, se essa necessidade torna urgente uma revisão das ideias básicas dos sistemas filosóficos tradicionais, é devido à completa mudança da vida social, paralela aos progressos da ciência, à revolução industrial e ao desenvolvimento da democracia. Não se podem efetuar essas mudanças na vida prática sem uma reforma educativa de acordo com elas, sem levar os homens a perguntar-se que ideias e ideais existem implícitos nessas transformações sociais, e que mudanças elas requerem nas ideias e ideais herdados das velhas e dessemelhantes culturas (1979, p. 364-365, grifo nosso). 
Dewey fez a ressalva de que a filosofia da educação "não é a aplicação de ideias já feitas a um sistema de prática escolar" (1979, p. 364). Essa visão idealista é rejeitada pelo filósofo, que defendeu o papel da filosofia como "formulação explícita dos problemas da formação de uma mentalidade reta e de bons hábitos morais, tendo-se em vista as dificuldades da vida social contemporânea" (1979, p. 364). Assim, a filosofia da educação se ocuparia da formulação de problemas da formação em estreita conexão com as dificuldades da vida social, pois, como salientaram Cruz e Cunha (2016), no pensamento de Dewey, a reflexão filosófica em educação emerge das problemáticas sociais.

A filosofia de Dewey surge "no transtorno, na confusão, nos atritos, nos fragmentos nos quais as maneiras habituais ou institucionais de agir se revelam insuficientes com referência a sua situação dada" (GREGORATTO, 2017, p. 14, tradução nossa). Desse modo, tanto a filosofia como a educação não são concebidas com parâmetros estanques. Segundo Cappa, é correto compreender que:

[...] a interação, a transação, postulado da filosofia da educação de Dewey se torna um instrumento ético e político [...] e, nesta perspectiva, a sua filosofia da educação não só encontra o seu fundamento em uma filosofia da experiência, mas se torna uma ética da prática educativa profeticamente atual (2014, p. XXII, tradução nossa).

Da mesma forma como filosofia e educação são inseparáveis no pensamento de Dewey, igualmente, os aspectos éticos, políticos e sociais são inerentes a essa relação.

\section{Considerações finais}

Para Dewey (1979), a filosofia e a educação são duas atividades humanas vinculadas entre si e inseparáveis. A afirmação de que a filosofia é a teoria geral da educação representa bem esse argumento. A filosofia deve ser educativa, ajudar na solução de problemas individuais, sociais e culturais. Uma filosofia fechada em si mesma seria inócua e estéril. Assim, Dewey viu uma função social e pedagógica para a filosofia. Tal função ajudaria a livrar a educação e, especialmente, a escola de uma rotina burocrática e uma monotonia cinzenta, conferindo dinamismo e vivacidade à prática educativa. As razões para defender os vínculos entre filosofia e educação são históricas na visão deweyana e remontariam à atuação dos sofistas, considerados pelo pensador norte-americano como os primeiros profissionais da educação. Os primeiros professores foram, portanto, filósofos. 
Na obra Democracia e educação, foi elaborada a concepção de filosofia da educação de Dewey, sobretudo no capítulo 24, no qual o autor fez uma revisão crítica de seu livro. É verdade que a noção de filosofia da educação forjada pelo autor não está restrita a essa publicação, ela se encontra difusa em toda a sua produção intelectual. Porém, em tal obra, o filósofo tratou de fixar os fundamentos que caracterizam a sua concepção de filosofia da educação.

Para isso, como de hábito, realizou a crítica dos sistemas filosóficos clássicos, marcados por dualismos que impedem a unidade da experiência e do conhecimento, vértice principal de sua filosofia. Criticou o estoicismo, a escolástica, o racionalismo, o empirismo, o positivismo e o próprio liberalismo. Outra característica importante é que a filosofia está ao alcance de todos, não é elitista e tão pouco aristocrática, destinada a uma casta de filósofos privilegiados. Todos os seres humanos podem filosofar, na medida em que forem sensíveis e formarem sua mentalidade para resolver os problemas práticos da vida. Dewey reconheceu o valor da filosofia "caseira" ou popular, mostrando que essas concepções surgem diante da dificuldade de a filosofia se aproximar da sociedade. $\mathrm{Na}$ medida em que a filosofia se isola da sociedade, preocupando-se apenas com suas ideias encerradas em si mesmas, há o aparecimento dessas filosofias populares.

A ideia de que a filosofia é a teoria geral da educação não é consensual. Isso permite que a crítica acuse tal tese de defender uma visão instrumental da filosofia, que abdique da sua dimensão crítica. Indagar sobre o sentido da presença da filosofia, particularmente da filosofia da educação, no currículo dos cursos de formação de professores e de pedagogia, é uma tarefa importante. Dewey teria muito a contribuir nesse ponto. Em favor do seu argumento, podemos sustentar que o exercício da crítica é um postulado metodológico da sua filosofia. Ao defender que a filosofia cumpra uma função específica na educação, Dewey não defendeu uma concepção meramente instrumental, distante da crítica, da política e da ética. Seu intento foi justamente favorecer uma maior aproximação da filosofia com os problemas sociais e com a vida da própria sociedade e dos indivíduos. Isso ainda causa algum incômodo, uma vez que significa retirar a filosofia da sua zona de conforto e inseri-la no contexto dos problemas sociais.

\section{Notas}

1 Em 1884, Dewey defendeu sua tese de doutorado sobre a psicologia no pensamento de Kant.

2 Dewey publicou a obra The influence of Darwin on philosophy and other essays em 1910. 


\section{Referências}

AMARAL, Maria Nazaré de Camargo Pacheco. Dewey: filosofia e experiência democrática. São Paulo: Perspectiva; Edusp, 1990.

BAIRATI, Piero. Presentazione. In: DEWEY, John. Esperienza e natura. Milão: Mursia, 2014. p. 5-10.

BERNSTEIN, Richard. Sul pragmatismo: l'eredità di Peirce, James e Dewey nel pensiero contemporaneo. Milão: Il Saggiatore, 2015.

BOURDIEU, Pierre. A economia das trocas simbólicas. 8. ed. São Paulo: Perspectiva, 2015.

CAPPA, Francesco. Introduzione. In: DEWEY, John. Esperienza e educazione. Milão: Raffaello Cortina, 2014. p. VII-XXII.

CHOMSKY, Noam. A responsabilidade dos intelectuais, redux. In: . Quem manda no mundo? São Paulo: Planeta, 2017. p. 13-31.

CRUZ, Paulo Fernando Aleixo da; CUNHA, Marcus Vinicius. A história da filosofia no discurso de John Dewey sobre a moral. Perspectiva, Florianópolis, v. 34, n. 1, p. 286-304, jun. 2016. Disponível em: <https://periodicos.ufsc.br/index.php/perspectiva/article/view/2175-795X.2016v34n1p286/31944>. Acesso em: 17 nov. 2017.

CUNHA, Marcus Vinicius. John Dewey: uma filosofia para educadores em sala de aula. Petrópolis: Vozes, 1998.

John Dewey: a utopia democrática. Rio de Janeiro: DP\&A, 2001.

DELEUZE, Gilles; GUATTARI, Félix. O que é a filosofia? 3. ed. São Paulo: Editora 34, 2013.

DEWEY, John. A criança e o programa escolar. In: Vida e educação. 10. ed. São Paulo: Melhoramentos, 1978. p. 42-62.

A filosofia em reconstrução. São Paulo: Companhia Editora Nacional, 1958.

. Democracia e educação. 4. ed. São Paulo: Companhia Editora Nacional, 1979.

Teoria da vida moral. São Paulo: Abril Cultural, 1980.

FÁVERO, Altair Alberto; TONIETTO, Carina (Org.). Leituras sobre John Dewey e a educação. Campinas: Mercado de Letras, 2011.

FREGA, Roberto. Una logica per il giudizio di pratica. In: DEWEY, John. Logica sperimentale: teoria naturalista della conoscenza e del pensiero. Macerata: Quodlibet, 2008. p. VII-XXXVII.

GALIANI, Claudemir. Educação e democracia em John Dewey. Maringá: Eduem, 2009.

GREGORATTO, Federica. Introduzione. In: DEWEY, John. Filosofia sociale e politica: lezioni in Cina (1919-1920). Torino: Rosenberg \& Sellier, 2017. p. 7-25.

PITOMBO, Maria Isabel Moraes. Conhecimento, valor e educação em John Dewey. São Paulo: Pioneira, 1974. 
SAVIANI, Dermeval. A filosofia na formação do educador. In: Educação: do senso comum à consciência filosófica. 19. ed. Campinas: Autores Associados, 2013a. p. 11-29. dos, 2013b.

Educação: do senso comum à consciência filosófica. 19. ed. Campinas: Autores AssociaEscola e democracia. 32. ed. Campinas: Autores Associados, 1999.

SCHMITZ, Egidio Francisco. O pragmatismo de Dewey na educação. Rio de Janeiro: Livros Técnicos e Científicos, 1980.

WARDE, Mirian Jorge. Notas sobre as fontes de formação de John Dewey com base no próprio autor. Educar em Revista, Curitiba, n. 48, p. 169-186, jun. 2013. Disponível em: <http://www. scielo.br/scielo.php?script=sci_arttext\&pid=S0104-40602013000200011\&lng=pt\&nrm=iso $>$. Acesso em: 17 nov. 2017. 